\title{
Estudo comparativo entre citopatologia e histopatologia no diagnóstico de neoplasias caninas ${ }^{1}$
}

\author{
Adelaide M. Magalhães ${ }^{2}$, Regina R. Ramadinha ${ }^{3}$, Cláudio S. L. Barros ${ }^{4}$ e Paulo V. \\ Peixoto $^{5}$
}

\begin{abstract}
Magalhães A.M., Ramadinha, R.R., Barros C.S.L. \& Peixoto, P.V. 2001. [A comparative study between cytology and histopathology for the diagnosis of canine neoplasms] Estudo comparativo entre citopatologia e histopatologia no diagnóstico de neoplasias caninas. Pesquisa Veterinária Brasileira 21(1):23-32. Universidade Federal Rural do Rio de Janeiro, Seropédica, RJ 23851-970, Brazil.

A comparative study between cytology and histopathology of various neoplasms from 150 dogs was carried out. Several staining methods including Wright, May-Grünwald-Giemsa, NewMethylene Blue and Papanicolau, and histological staining methods such as Hematoxilin \& Eosin, van Gieson, Sudan, Toluidine Blue and Periodic Acid Schiff were used. The data obtained indicated an $85.3 \%$ accuracy for the cytological diagnosis when the histopathological diagnosis was considered as the correct parameter. In $4.0 \%$ of the cases only the embrionary origin of the neoplasms was determined, and in $1.3 \%$ only the prognosis was established. The cytological diagnosis differed from the histopathological diagnosis in $8.1 \%$ of the cases. In two cases (1.3\%), although the cytological and histopathological diagnoses differed, a reexamination determined that the former was correct which increased its accuracy up to $86.6 \%$. Fine needle aspiration biopsy proved to be the best technique to obtain samples for the study. Cytology was found not suitable for the diagnosis of mammary neoplasms due to the wide variation of the cytological aspects from different areas. The imprint on slides is a technique not recommended to evaluate mesenchymal tumors and should be replaced by exfoliative cytology. The Wright method proved to be the more efficient staining method. Adapted staining methods from histopathology such as van Gieson for leiomyomas and leiomyosarcomas, Sudan Black B for lipomas and liposarcomas, and Periodic Acid of Schiff and Toluidine Blue for mastocytomas, were especially useful in visualizing the fine morphological details of various epithelial and mesenchymal neoplasms examined.
\end{abstract}

INDEX TERMS: Cytology, histopathology, staining, diagnosis, neoplasms.

\footnotetext{
${ }^{1}$ Aceito para publicação em 8 de Fevereiro de 2001.

Parte da dissertação de mestrado do primeiro autor defendida no Curso de Pós-Graduação em Medicina Veterinária, Área de Concentração em Clínica Médica, Universidade Federal Rural do Rio de Janeiro (UFRRJ) em 20 de outubro de 1998.

${ }^{2}$ Clínica Médica, Universidade Estácio de Sá, Av. Boca do Mato 850, Vargem Pequena, Rio de Janeiro, RJ 22783-320.

${ }^{3}$ Depto Medicina e Cirurgia, UFRRJ, Km 47, Seropédica, RJ 23851-970.

${ }^{4}$ Depto Patologia, Universidade Federal de Santa Maria (UFSM), Santa Maria, RS 97105-900.

${ }^{5}$ Depto Nutrição Animal e Pastagem, UFRRJ, Seropédica, RJ 23851-970; bolsista do CNPq (302342/86-VT).
}

RESUMO.- Foi realizado um estudo comparativo entre os diagnósticos citológico e histopatológico em diversas neoplasias de 150 cães, pelas colorações de Wright, May-GrünwaldGiemsa, Novo Azul de Metileno e Papanicolau. Colorações histológicas como Hematoxilina-Eosina, van Gieson, Sudan, Azul de Toluidina e Ácido Periódico de Schiff também foram empregadas. Os dados revelaram uma eficácia de ordem de $85,3 \%$ no diagnóstico citopatológico, considerando-se os resultados histopatológicos como corretos. Em $4,0 \%$ dos casos somente a origem embrionária das neoplasias foi estabelecida. Em 1,3\% das neoplasias apenas o prognóstico foi determinado; o diagnóstico citológico diferiu da histopatologia em $8,1 \%$ 
dos casos. Em dois casos $(1,3 \%)$ o diagnóstico citológico diferiu do histológico, mas um reexame determinou que o primeiro estava correto, o que elevou a sua eficácia para 86,6\%. Entre as técnicas utilizadas, a punção aspirativa por agulha fina foi o melhor método para obter amostras. A citologia não foi adequada para o diagnóstico de neoplasias mamárias, dadas às variações morfológicas em diferentes áreas. $\mathrm{A}$ impressão em lâmina não é recomendada para análise de tumores mesenquimais e deve ser substituída pela citologia esfoliativa. O Wright revelou-se o método de coloração mais eficiente. As colorações adaptadas da histopatologia, van Gieson em leiomiomas e leiomiossarcomas, Sudan em lipomas e lipossarcomas, e Ácido Periódico de Schiff e Azul de Toluidina em mastocitomas, foram empregadas com sucesso fornecendo assim maior clareza de detalhes para as diversas neoformações de origem epitelial e mesenquimal.

TERMOS DE INDEXAÇÃO: Citologia, histopatologia, corantes, diagnóstico, neoplasias.

\section{INTRODUÇÃO}

O exame citopatológico propicia diagnósticos rápidos, sem risco anestésico, além de ser bastante acessível do ponto de vista econômico. As informações determinadas por esse método direcionam as condutas clínica (quimioterapia, radioterapia) e cirúrgica.

Considerando-se o estado ainda incipiente da citopatologia em medicina veterinária, este estudo objetivou, em primeiro lugar, comparar a eficiência dessa técnica com a obtida em exames histopatológicos de rotina em diversas neoplasias de cães. Adicionalmente são testadas, na citopatologia, algumas técnicas de coloração adaptadas da rotina histopatológica, no intuito de verificar a viabilidade de sua aplicação no diagnóstico citopatológico.

\section{Revisão de Literatura}

\section{Histórico}

Em medicina humana, a citopatologia é empregada desde o século XIX (Castillo et al. 1988, Carvalho 1993). Em 1867 , Leucke \& Klebs estudaram células de líquido ascítico em pacientes com tumores ovarianos, enquanto em 1917, Papanicolau iniciou suas pesquisas sobre citologia esfoliativa, tendo estabelecido, em 1928, o diagnóstico de carcinoma uterino a partir da secreção vaginal de mulheres (Boon et al. 1982, Felizzola 1995). Dentro da medicina veterinária brasileira, este método diagnóstico é relativamente novo, ganhando algum incremento no final da década de 1980 (Silveira 1988, Guedes et al. 1997).

Felizzola (1995) obteve dados estatísticos de neoplasias da cavidade oral, comparando seus resultados com os achados clínico-laboratoriais e histopatológicos. Faz-se referência ao emprego da punção aspirativa por agulha fina (PAAF), com eficácia na ordem de $86,4 \%$, quando comparada ao exame histopatológico das principais neoplasias dos animais domésticos (Bracarense et al. 1993, Castro et al. 1993, Guedes et al. 1997). Schwartz et al. (1994) também determinaram os aspectos clínico-laboratoriais do linfossarcoma com diagnós- tico firmado através do exame clínico-citopatológico. Ramadinha et al. (1995) analisaram a ocorrência de tumores cutâneos em cães e gatos no Hospital Veterinário do Instituto de Veterinária da Universidade Federal Rural do Rio de Janeiro e determinaram a eficácia da PAAF e da citopatologia esfoliativa em $82 \%$ dos casos. No trabalho de tese de Coelho (1996), o diagnóstico de tumor venéreo transmissível canino (TVT) foi obtido apenas através da impressão do tecido tumoral em lâmina, enquanto Mello \& Santos (1996) verificaram características celulares típicas da neoplasia a partir da citopatologia esfoliativa. Em um outro trabalho, Mello et al. (1996) preconizaram a mesma técnica para acompanhar a remissão do TVT em cadelas tratadas com vincristina.

Xavier et al. (1997) utilizaram a citopatologia como único meio diagnóstico complementar para TVT, para posterior quimioterapia com vinblastina. De Paula et al. (1997) confirmaram metástase de TVT através da citopatologia aspirativa de fígado e baço, enquanto Melchert et al. (1997) e Rocha et al. (1997) observaram células metastáticas de TVT cutâneo em linfonodos periféricos, após coloração de Giemsa. Com o emprego conjunto da ultrassonografia e citopatologia aspirativa, Machado et al. (1997a) detectaram a ocorrência de linfossarcoma esplênico em um cão. 0 diagnóstico definitivo foi determinado através da histopatologia do órgão. Um caso de metástase de mieloma múltiplo intratorácico foi diagnosticado através da citopatologia aspirativa de órgãos do sistema fagocitário mononuclear (Machado et al. 1997b).

Aspectos gerais e comparativos da técnica citopatológica Enfatiza-se entre os objetivos da citopatologia, a diferenciação entre processos inflamatórios, hiperplasias e neoplasias, com estabelecimento do prognóstico do tumor e identificação de sítios metastáticos para rápida ação no tratamento e monitoramento de recidiva local (Barton 1983, Allen \& Prasse 1986, Silveira 1988, Cowell \& Tyler 1989a, Wellman 1990, Peterson \& Couto 1994, Ogilvie \& Moore 1995, Montes O. 1997).

As principais vantagens do exame citopatológico são a rapidez e a simplicidade com que se estabelece o diagnóstico do quadro mórbido. Acrescenta-se o fato de ser um método seguro, que não proporciona riscos à vida do paciente, não requerendo equipamento sofisticado, sedação ou anestesia para sua realização (Tvedten 1981, Mills \& Griffiths 1984, Cowell \& Tyler 1989a, Mills 1989, Peterson \& Couto 1994, Wellman 1996, Guedes et al. 1997). De um modo geral, as amostras citopatológicas são facilmente obtidas, já que muitas formas de colheita são pouco invasivas e o grau de morbidade e/ou complicações tardias, associadas com as mesmas, são mínimas (Couto 1994).

Na experiência de O'Rourke (1983) e Meyer \& Franks (1986a), a segurança da informação obtida pela citopatologia depende da qualidade da técnica e confeç̧ão das lâminas. A coloração e a interpretação da amostra também são de fundamental importância para o sucesso da citopatologia (Cunha 1987, Meyer 1987), cuja precisão pode variar de 63 a 97\%, dependendo do tipo e da localização da neoplasia e da perícia do citopatologista (Mills \& Griffiths 1984). 
Duncan \& Prasse (1979) relatam situações em que o diagnóstico citopatológico é mais fácil do que o exame histopatológico. Cita-se como exemplo, as granulações nos mastocitomas, os detalhes celulares nas linfoproliferações e os grânulos de melanina em melanomas (O'Rourke 1983). Montes O. (1997) acrescenta que, nos casos de alguns sarcomas e leucemias, o exame citopatológico de PAAF possui melhor eficácia para o diagnóstico do que a histopatologia. Na literatura veterinária, estudos comparativos entre as duas técnicas demonstram que a histopatologia permite um diagnóstico mais definitivo por proporcionar uma visão de conjunto, onde a arquitetura tecidual está completa (Barton 1983, Meyer \& Franks 1986a, Hewicker et al. 1990, Tvedten 1994). Ogilvie \& Moore (1995) afirmam que, em geral, a histopatologia apresenta maior precisão quando associada aos resultados da citopatologia, como no diagnóstico de neoplasias da cavidade oral de cães e gatos. Mills \& Griffiths (1984) e Morrison \& DeNicola (1993) ainda enfatizam que se deve considerar a utilidade da citopatologia e histopatologia dentro da clínica médica, sem olvidar que estas duas técnicas complementam uma a outra.

As principais complicações da citopatologia seriam hemorragia, infecção, injúria ao tecido adjacente e disseminação de células neoplásicas, fatos considerados raros (Wellman 1996). A observação de Tvedten (1994) confirma algumas limitações da citopatologia como método diagnóstico. A abordagem por ele defendida relaciona-se à descrição da neoplasia, que não é específica, sendo tão somente reconhecida como um carcinoma ou sarcoma. Os erros de diagnóstico relacionam-se também aos problemas de coloração. Pode-se confeccionar amostras muito ou pouco coradas, ou coradas de forma irregular e, em alguns casos, com presença de precipitados ou outros tipos de artefatos refráteis, que dificultam a avaliação (O’Rourke 1983, Cowell \& Tyler 1989a).

\section{Colheita e preparação de amostras}

De acordo com Cowell \& Tyler (1989a,b), a técnica para obtenção de espécimes e preparação de lâminas varia conforme a localização anatômica e as características do tecido neoplásico, do animal e das anormalidades clínicas desencadeadas pela neoplasia. As amostras podem ser obtidas de diversas maneiras, através de aspirados com agulha fina (PAAF), da impressão de tecidos sólidos ("imprint"), "swab" e da técnica esfoliativa (Susaneck 1983, Cowell \& Tyler 1989a, Moriello \& Rosenthal 1990, Wellman 1996, Montes O. 1997). $O$ advento da ultrassonografia também tem auxiliado na obtenção de amostras de diferentes órgãos envolvidos em patologias do tipo inflamatório ou neoplásico, diminuindo os riscos de complicações (Withrow \& MacEwen 1996, Wellman 1996).

Segundo O'Rourke (1983) e Edwards (1994a), a técnica de citopatologia aspirativa (PAAF) é a mais comumente empregada por ser um método simples para diferenciar uma reação tecidual inflamatória de uma neoplasia (Allen \& Prasse 1986, Meyer \& Franks 1986a, Cowell \& Tyler 1989a, Tvedten 1994, Burkhard \& Meyer 1996). Por ser mínima a lesão provocada pela agulha fina, a predisposição para ocasionar metástases, em casos de neoplasias malignas, torna-se insig- nificante em comparação à biópsia cirúrgica (Guedes et al 1997). A antissepsia é fundamental quando da colheita de espécimes intracavitários, técnica invasiva, que acompanhada pela ultrassonografia tem riscos diminuídos (Meyer 1987, Cowell \& Tyler 1989a, Couto 1994, Burkhard \& Meyer 1996, Guedes et al. 1997). Biópsias por agulha fina em casos de coagulopatias e hemangiossarcoma esplênico são contraindicadas (Ogilvie \& Moore 1995, Burkhard \& Meyer 1996).

A técnica de PAAF consiste no isolamento manual do campo a ser incidido e na introdução de uma agulha fina (calibre 20,23 ou 25) acoplada a uma seringa estéril de 10 a $20 \mathrm{ml}$. Esta é introduzida 3 a 4 vezes, em pontos diversos do nódulo ou massa tumoral, mantendo a pressão de 6 a $8 \mathrm{ml}$, no interior da seringa. Antes de ser removida, deve-se liberar a pressão de dentro da seringa, retornando o êmbolo à posição inicial. O espécime é, então, colocado sobre lâmina seca e limpa, confeccionando-se o esfregaço em, no mínimo, três lâminas (Seybold et al. 1982, O'Rourke 1983, Mills \& Griffiths 1984, Allen \& Prasse 1986, Meyer 1987, Cowell \& Tyler 1989a, Couto 1994, Peterson \& Couto 1994, Ogilvie \& Moore 1995, Guedes et al. 1997, Montes O. 1997). Já nos casos de osteocondrossarcomas ou osteossarcomas, o emprego de agulha calibre $40 \times 12$ permite obter-se material mais adequado para análise citopatológica, visto tratar-se de neoplasias de consistência dura e pouco esfoliativas (Ramadinha 1996). A técnica de comprimir o material entre lâminas é contraindicada, principalmente, em aspirados de linfonodo, porquanto pode ocorrer ruptura celular (Wellman 1990).

O método de impressão ("imprint") é feito de amostras de biópsias cirúrgicas antes destas serem fixadas em formol a $10 \%$, sendo utilizado para neoplasias cuja formação tecidual seja bastante celular ou pouco fibrosa (O'Rourke 1983, Meyer \& Franks 1986a). Esta técnica não é comumente indicada para neoplasias ulceradas, porquanto uma reação inflamatória secundária pode inviabilizar o diagnóstico. O "swab" torna-se útil para colheita de amostras de tratos fistulosos (O'Rourke 1983, Cowell \& Tyler 1989b, Montes O. 1997). A citopatologia esfoliativa tem como indicação tumores fibrosos, seromas, sialoceles e cistos, ou para efusões secundárias a processos metastáticos obstrutivos, através da colheita de líquido com EDTA, seguida de centrifugação (Humason 1962, O'Rourke 1983, Allen \& Prasse 1986, Meyer \& Franks 1986a, Cowell \& Tyler 1989a, Clinkenbeard 1992, Ogilvie \& Moore 1995, Burkhard \& Meyer 1996). A colheita de espécimes citopatológicos da cavidade nasal pode ser realizada mediante técnicas aspirativas ou lavagem (Meyer 1987), meio diagnóstico pouco invasivo, que, geralmente, não requer intervenção cirúrgica (French 1987). As neoplasias do sistema reprodutor podem ser determinadas a partir da análise do fluido prostático, aspirado testicular, colpocitologia e secreção mamária, enquanto o achado celular atípico de sedimento urinário, denota envolvimento neoplásico do trato urinário (Allen \& Prasse 1986, Wellman 1990, Vannucchi et al. 1997).

\section{Colorações em citopatologia}

A fixação dos esfregaços deve ser imediata para preservação da estrutura celular, conservação dos detalhes citopatológicos, podendo ser feita pelo álcool etílico ou 
metílico. A escolha depende do material a ser examinado, do que se pretende estudar e da técnica de coloração a ser utilizada (Humason 1962, Cunha 1987, Ramadinha 1996, Piza 1997).

Os métodos citoquímicos baseiam-se em reações químicas dos corantes com componentes de células fixadas em lâmina, que são identificadas pelo exame microscópico (SBHH 1975). Os corantes básicos utilizados na rotina de diagnóstico são o Romanowsky (Diff-Quick, Wright, Giemsa, MayGrünwald-Giemsa e Leishman), o Novo Azul de Metileno (NAM), o Papanicolau (Humason 1962, O'Rourke 1983, Meyer 1987, Wellman 1990, Tvedten 1994, Ogilvie \& Moore 1995, Montes O. 1997) e a Hematoxilina-Eosina (Cunha 1987, Piza 1997). Os corantes Papanicolau e Tricrômico de Sano (Papanicolau modificado) são mais amplamente utilizados em ginecologia humana (Tvedten 1981, Meyer 1987). O tempo de coloração está diretamente relacionado à espessura do material, o tempo em que foi confeccionado o corante e ao tipo de coloração (Cowell \& Tyler 1989a,b, Piza 1997). Cowell \& Tyler (1989a) recomendam que algumas lâminas sejam armazenadas apenas fixadas para possíveis colorações subseqüientes. Na confecção de amostras citopatológicas, Couto (1994) demonstrou haver acentuadas diferenças entre as diversas técnicas de coloração. A tinção pelos corantes de Romanowsky despende um pouco mais de tempo que o NAM, porém fornece detalhes celulares e contrastes melhores entre núcleo e citoplasma, sendo também considerada como coloração permanente (O'Rourke 1983, Olson et al. 1984a, Allen \& Prasse 1986, Meyer 1987, Couto 1994, Burkhard \& Meyer 1996). Em contrapartida, os detalhes intranucleares não ficam bem definidos (Allen \& Prasse 1986). O NAM é uma coloração rápida, cujos esfregaços corados não podem ser guardados para posterior consulta e o contraste de cor não é bem marcado, evidenciando apenas núcleo e nucléolo (O'Rourke 1983, Olson et al. 1984a, Meyer 1987, Wellman 1990, Couto 1994, Ogilvie \& Moore 1995). Meyer \& Franks (1986b) fazem referência ao corante de Papanicolau como capaz de permitir uma análise precisa de núcleo e nucléolo. O padrão de cromatina fica distinto e próprio para análise, facilitando a observação das aberrações morfológicas, sugestivas de neoplasias (Boon et al. 1982, O'Rourke 1983, Cowell \& Tyler 1989a, Rebar et al. 1989, Ogilvie \& Moore 1995). Em contrapartida, os reagentes de Papanicolau são de preparação e manutenção difíceis na clínica diária, quando comparados aos corantes do tipo Romanowsky, fazendo com que seu uso se restrinja às patologias específicas (Allen \& Prasse 1986, Meyer \& Franks 1986b, Wellman 1990, Schmitt 1995, Piza 1997). Em alguns tipos de mastocitoma, além dos corantes do tipo Romanowsky e NAM, pode-se utilizar o Azul de Toluidina ou o Ácido Periódico de Schiff (PAS) para melhor demonstração dos grânulos (Susaneck 1983), bem como em casos de mastocitomas epitelióides pouco diferenciados (Meyer \& Franks 1986b, Lemarié et al. 1995, Piza 1997).

\section{MATERIAL E MÉTODOS}

No período de março de 1996 a novembro de 1997, foram selecionados 150 cães, entre machos e fêmeas, com idades entre $2 \mathrm{e}$
20 anos e de diferentes raças, que apresentaram neoformações em locais diversos. Os atendimentos clínicos e as colheitas de material foram realizados no Setor de Dermatologia do Hospital Veterinário de Pequenos Animais e os estudos histopatológicos conduzidos no Laboratório de Anatomia Patológica do Departamento de Epidemiologia e Saúde Pública, ambos do Instituto de Veterinária da Universidade Federal Rural do Rio de Janeiro.

A PAAF foi realizada em todos os tipos de neoplasias com utilização de agulha $25 \times 7$ acoplada a uma seringa de $12 \mathrm{ml} \operatorname{com~} 2 \mathrm{ml}$ de ar em seu interior. Nos osteossarcomas optou-se pelo emprego de agulha 40x12, a fim de se obter uma amostra mais representativa. Os tumores de origem epitelial, bem como TVTs, histiocitomas, linfossarcomas e mastocitomas foram também submetidos à técnica de "imprint". A citopatologia esfoliativa foi empregada a partir da escarificação das neoplasias ou de amostras colhidas por biópsia. Já as efusões secundárias aos tumores metastáticos e o líquido das neoplasias císticas foram previamente centrifugados para posterior confecção dos esfregaços. Com o intuito de minimizar as alterações observadas, optou-se por confeccionar 10 lâminas de cada neoplasia estudada.

As lâminas confeccionadas, após secagem ao ar, foram coradas com Wright, May-Grünwald-Giemsa (MGG) e Novo Azul de Metileno (NAM) para o estudo preliminar. Nas amostras fixadas de imediato pela imersão em álcool hidratado $\left(96^{\circ} \mathrm{G}\right)$ foram utilizados corantes de Papanicolau, Hematoxilina-Eosina (HE) e Ácido Periódico-Schiff (PAS). As lâminas a serem submetidas à coloração de Azul de Toluidina não eram fixadas, enquanto as amostras coradas por van Gieson e Sudan foram previamente tratadas pelo formol a $10 \%$. Estas colorações foram selecionadas de acordo com a origem embrionária do tumor e o tipo celular, definidos anteriormente pelos corantes do tipo Romanowsky e Papanicolau. As lâminas coradas eram montadas com lamínula e bálsamo do Canadá e examinadas à microscopia óptica. A exceção foi feita para lâminas de neoplasias mesenquimais de origem adiposa, coradas pelo Sudan e montadas em glicerina. Todos os diagnósticos foram anotados nas fichas clínicas. De cada animal também eram colhidas amostras por meio de biópsia cirúrgica, através de "punch" ou bisturi, fixadas e conservadas em solução de formol a $10 \%$ para processamento histopatológico.

Mediante os dados clínicos e cito-histopatológicos, procedeu-se ao estudo comparativo das diversas técnicas de diagnóstico empregadas e estabeleceu-se o seguinte critério para análise comparativa entre os resultados citopatológicos e os histopatológicos correspondentes:

Correto (1) - quando o diagnóstico citopatológico foi confirmado pelo histopatológico; Aproximado (2) - quando a citopatologia definiu a origem embrionária da neoplasia, mas o prognóstico foi incorreto; Parcialmente Correto (3) - quando a citopatologia definiu o prognóstico, mas a origem embrionária do tumor estava incorreta; Incorreto (4) - quando o diagnóstico citopatológico não estava de acordo com o diagnóstico histopatológico.

Para classificar a capacidade tintorial dos corantes, utilizaramse os seguintes parâmetros para qualificar a eficiência das colorações:

Ótima $(+++)$ - aquela que permitiu uma boa definição celular, com ótima qualidade tintorial, possibilitando um claro reconhecimento do tipo de neoplasia; Boa $(++)$ - aquela que proporcionou uma boa qualidade tintorial, mas cujo contraste celular não foi tão evidente ao ponto de definir com muita clareza o tipo celular neoplásico; Regular (+) - aquela cuja qualidade tintorial foi regular, necessitando submeter a amostra a um outro tipo de coloração para uma definição celular correta; Má (") - aquela cuja qualidade tintorial foi muito ruim e não permitiu uma definição celular, impossibilitando sobremaneira o diagnóstico; Sem indicação para o caso (-) - quando a coloração não foi indicada para o tipo neoplásico em estudo. 


\section{RESULTADOS}

Das 150 neoplasias estudadas neste experimento, $74(49,3 \%)$ eram mesenquimais, $26(17,3 \%)$ epiteliais, $7(4,7 \%)$ de origem neuroectodérmica, $7(4,7 \%)$ de células do cordão sexual e interstício e $16(10,7 \%)$ tumores venéreos transmissíveis. Realizou-se um estudo individual das neoplasias de glândulas mamárias (20 casos - 13,3\%), visto tratar-se de neoformações peculiares, com grande variedade celular dentro de uma mesma massa tumoral. A técnica citopatológica revelou uma eficácia da ordem de $85,3 \%$ (128 casos) quando comparada à histopatologia. Foi observado que em 4,0\% (6) dos tumores somente se definiu a origem embrionária das neoplasias, enquanto em $1,3 \%$ (2) se sugeriu apenas o prognóstico. 0 diagnóstico citopatológico diferiu completamente da histopato- logia em 8,1\% (12) dos casos. Em dois casos estudados, os achados citopatológicos foram diferentes do que foi descrito na histopatologia, mas após reavaliação das lâminas, a citopatologia foi a técnica que melhor caracterizou as neoplasias, permitindo se estabelecer o diagnóstico definitivo e elevando a eficácia para $86,6 \%$.

A PAAF foi melhor realizada com seringa plástica de 12 $\mathrm{ml}$ acoplada à agulha $25 \times 7$ e em neoplasias ósseas, com agulhas de calibre 40x12. A técnica de manter $2 \mathrm{ml}$ de ar dentro da seringa, antes de inserir a agulha no tecido neoplásico, facilitou a rápida colocação do material aspirado em lâmina, evitando perda do material para o interior da seringa, ressecamento da amostra e/ou formação de coágulo, em neoplasias altamente vascularizadas ou hemorrágicas. A PAAF

Quadro 1. Avaliação do diagnóstico citopatológico, métodos de colheita e eficiência das colorações

\begin{tabular}{|c|c|c|c|c|c|c|c|c|c|c|c|c|c|}
\hline \multirow{2}{*}{$\begin{array}{c}\text { Neoplasia } \\
\text { (No de casos) }\end{array}$} & \multicolumn{3}{|c|}{ Técnica de colheita } & \multicolumn{9}{|c|}{ Técnicas de coloração } & \multirow{2}{*}{$\begin{array}{l}\text { Diagnóstico } \\
\text { citopatológico }\end{array}$} \\
\hline & PAAF & IMP & ESF & WRI & MGG & NAM & PPN & $\mathrm{HE}$ & AT & PAS & VG & SUD & \\
\hline Mastocitoma (22) & $\mathrm{X}$ & $\mathrm{X}$ & $\mathrm{X}$ & +++ & ++ & +++ & ++ & ++ & +++ & ++ & - & - & 1 \\
\hline Hiperplasia linforreticular (1) & $\mathrm{X}$ & $\mathrm{X}$ & $\mathrm{X}$ & +++ & ++ & - & ++ & ++ & - & - & - & - & 2 \\
\hline Linfangioma (1) & $\mathrm{X}$ & $\mathrm{X}$ & $\mathrm{X}$ & +++ & ++ & - & ++ & ++ & - & - & - & - & 1 \\
\hline Linfossarcoma (6) & $\mathrm{X}$ & $\mathrm{X}$ & $\mathrm{X}$ & +++ & ++ & - & ++ & ++ & - & - & - & - & 1 \\
\hline Micose fungóide (1) & $\mathrm{X}$ & & $\mathrm{X}$ & +++ & ++ & - & ++ & ++ & - & - & - & - & 1 \\
\hline TVT (16) & $\mathrm{X}$ & $\mathrm{X}$ & $\mathrm{X}$ & +++ & ++ & - & ++ & ++ & - & - & - & - & 1 \\
\hline Histiocitoma canino (2) & $\mathrm{X}$ & & $\mathrm{X}$ & +++ & ++ & - & + & ++ & - & - & - & - & 1 \\
\hline Plasmocitoma cutâneo (12) & $\mathrm{X}$ & & $\mathrm{X}$ & +++ & + & - & + & ++ & - & - & - & - & $1 / 4$ \\
\hline Histiocitoma Fibroso maligno (2) & $\mathrm{X}$ & & $\mathrm{X}$ & +++ & + & - & + & ++ & - & - & - & - & 1 \\
\hline Melanoma benigno (1) & $\mathrm{X}$ & & $\mathrm{X}$ & +++ & ++ & - & + & + & - & - & - & - & 1 \\
\hline Melanoma maligno (6) & $\mathrm{X}$ & & $\mathrm{X}$ & +++ & ++ & - & + & + & - & - & - & - & 1 \\
\hline Osteossarcoma (3) & $\mathrm{X}$ & & $\mathrm{X}$ & +++ & +++ & - & + & ++ & - & - & - & - & 1 \\
\hline Condrossarcoma (1) & $\mathrm{X}$ & & $\mathrm{X}$ & +++ & ++ & - & + & ++ & - & - & - & - & 1 \\
\hline Osteocondrossarcoma (2) & $\mathrm{X}$ & & & +++ & ++ & - & + & ++ & - & - & - & - & 1 \\
\hline Lipoma (8) & $\mathrm{X}$ & & $\mathrm{X}$ & +++ & ++ & +++ & ++ & +++ & - & - & - & +++ & 1 \\
\hline Lipoma infiltrativo (1) & $\mathrm{X}$ & & $\mathrm{X}$ & +++ & ++ & +++ & ++ & ++ & - & - & - & +++ & 2 \\
\hline Lipossarcoma (3) & $\mathrm{X}$ & & $\mathrm{X}$ & +++ & ++ & + & + & ++ & - & - & - & +++ & 1 \\
\hline Fibrossarcoma (1) & $\mathrm{X}$ & & $\mathrm{X}$ & +++ & ++ & - & ++ & ++ & - & - & - & - & 1 \\
\hline Hemangioma (1) & $\mathrm{X}$ & & $\mathrm{X}$ & ++ & ++ & - & + & ++ & - & - & - & - & 1 \\
\hline Hemangiossarcoma (3) & $\mathrm{X}$ & & $\mathrm{X}$ & ++ & ++ & - & + & ++ & - & - & - & - & 1 \\
\hline Leiomioma (2) & $\mathrm{X}$ & & $\mathrm{X}$ & ++ & ++ & - & + & + & - & - & +++ & - & 1 \\
\hline Leiomiossarcoma (2) & & & $X$ & ++ & ++ & - & + & + & - & - & +++ & - & $1 / 2$ \\
\hline Tumor de células basais (4) & $\mathrm{X}$ & $\mathrm{X}$ & $\mathrm{X}$ & ++ & + & - & + & +++ & - & $*$ & - & - & 1 \\
\hline Carcinoma epidermóide (8) & $\mathrm{X}$ & $\mathrm{X}$ & $\mathrm{X}$ & +++ & ++ & - & + & * & - & $*$ & - & - & $1 / 4$ \\
\hline Epulis acantomatoso (1) & $\mathrm{X}$ & $\mathrm{X}$ & $\mathrm{X}$ & ++ & ++ & - & + & * & - & - & - & - & 2 \\
\hline Adenoma sebáceo (2) & $\mathrm{X}$ & $\mathrm{X}$ & $\mathrm{X}$ & +++ & + & - & + & ++ & - & - & - & - & $1 / 3$ \\
\hline Carcinoma sebáceo (1) & $\mathrm{X}$ & $\mathrm{X}$ & $\mathrm{X}$ & +++ & +++ & - & + & ++ & - & - & - & - & 1 \\
\hline Carcin. De gl. sudor. Apócrina (3) & $X$ & $\mathrm{X}$ & $\mathrm{X}$ & ++ & * & - & + & ++ & - & - & - & - & $1 / 4$ \\
\hline Cistoadenoma apócrino (1) & $\mathrm{X}$ & & $\mathrm{X}$ & + & * & - & + & + & - & - & - & - & 4 \\
\hline Cistos epidermais (1) & $\mathrm{X}$ & & & + & ++ & - & + & + & - & - & - & - & 3 \\
\hline Adenoma de gls. Hepatóides (2) & $X$ & $\mathrm{X}$ & $\mathrm{X}$ & +++ & +++ & - & + & ++ & - & - & - & - & 1 \\
\hline Carcinoma de gls. Hepatóides (1) & 1) $X$ & $\mathrm{X}$ & $\mathrm{X}$ & +++ & ++ & - & + & ++ & - & - & - & - & 1 \\
\hline Carcin. de gls. Ceruminosas (1) & $\mathrm{X}$ & & $\mathrm{X}$ & ++ & * & - & + & ++ & - & - & - & - & 1 \\
\hline Carcinoma de céls. Renais (1) & $\mathrm{X}$ & $\mathrm{X}$ & $\mathrm{X}$ & +++ & +++ & - & + & ++ & - & - & - & - & 1 \\
\hline Sertolioma (2) & $\mathrm{X}$ & $\mathrm{X}$ & $\mathrm{X}$ & +++ & ++ & - & + & ++ & - & - & - & - & 1 \\
\hline Seminoma (3) & $\mathrm{X}$ & $\mathrm{X}$ & $\mathrm{X}$ & +++ & ++ & - & + & ++ & - & - & - & - & 1 \\
\hline Tumor de céls. de Leydig (2) & & $\mathrm{X}$ & $\mathrm{X}$ & +++ & ++ & - & + & ++ & - & - & - & - & 1 \\
\hline Neoplasias mamárias (20) & $\mathrm{X}$ & $\mathrm{X}$ & $\mathrm{X}$ & +++ & ++ & - & - & ++ & - & - & - & - & $1 / 2 / 4$ \\
\hline
\end{tabular}

Legenda:

PAAF - Punção Aspirativa por Agulha Fina; IMP - "Imprint"; ESF - Esfoliativa. +++ Ótima; ++ Boa; + Regular; " Má; - Sem indicação para o caso. 1 - Correto; 2 -Aproximado; 3 - Parcialmente correto; 4 - Incorreto.

WRI - Wright; MGG - May-Grünwald-Giemsa; NAM - Novo Azul de Metileno; PPN - Papanicolau; HE - Hematoxilina-Eosina; AT - Azul de Toluidina; PAS - Ácido. 
de neoplasias mamárias teve emprego limitado dadas a consistência dura dos tumores mistos e a variação do padrão histológico da neoplasia, de área para área. Constatou-se também dificuldade de realizar a PAAF em alguns tumores mesenquimais, como os leiomiomas, por estes possuírem estrutura muito firme. Neste caso, empregou-se a técnica de escarificar o tecido e distribuir o material sobre a lâmina.

$\mathrm{O}$ método esfoliativo mostrou-se simples e rápido, uma vez que a esfoliação permitiu obter material rico, com número maior de células por campo de análise citológica. Todavia, verificou-se, por vezes, dificuldade de diagnóstico, em função da inflamação secundária, quando o material foi colhido a partir de áreas ulceradas e/ou com necrose. Muitos tumores epiteliais mostraram-se mais esfoliativos por possuírem pouco estroma. Alguns mastocitomas esquirrosos foram submetidos às três formas de colheita de amostras, sendo a técnica esfoliativa a mais eficaz para confecção de lâminas. Por outro lado, em outros casos de mastocitomas, bem como linfossarcomas, TVTs e adenomas a ruptura celular, decorrente da esfoliação, fez com que o material nuclear dificultasse o exame citológico da neoplasia.

Alguns tumores encontravam-se secundariamente inflamados, fato que dificultou a visualização e identificação de células neoplásicas. Dada a pressão, células epiteliais e de alguns histiocitomas, por vezes, assumiam conformação fusiforme, confundindo-se com tumores de origem mesenquimal.

O álcool hidratado $\left(96^{\circ} \mathrm{G}\right)$ teve boa capacidade fixadora, proporcionando uma diferenciação celular ideal para uma correta coloração e impregnação tintorial dos corantes de HE, Papanicolau e PAS.

As lâminas fixadas em álcool metílico (metanol) e formol a $10 \%$, não se prestaram para as colorações de Papanicolau, Azul de Toluidina e PAS. Já as amostras de neoplasia de musculatura lisa e de tecido adiposo, que foram fixadas em formol $10 \%$ e coradas com van Gieson e Sudan, não demonstraram evidências de alteração na morfologia celular. Esse meio de

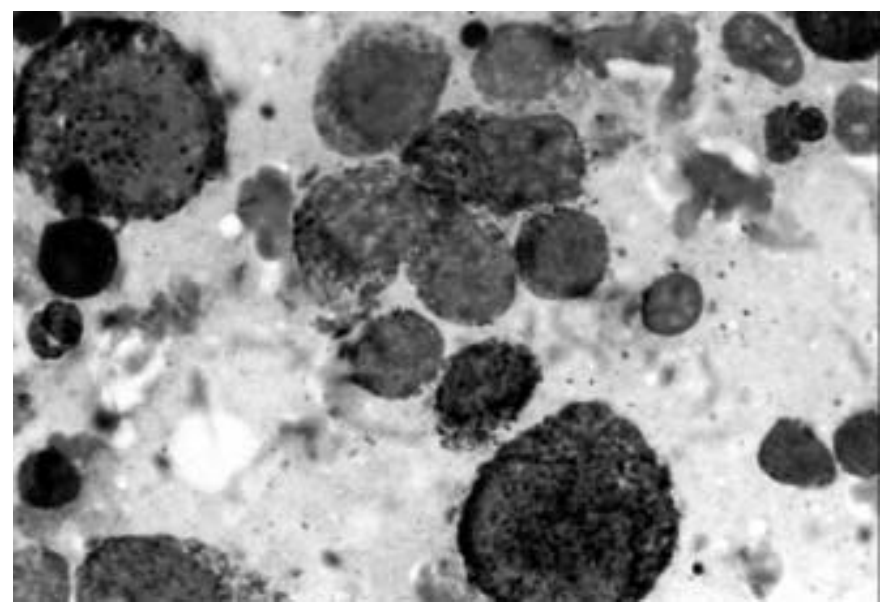

Fig. 1. "Imprint" de Mastocitoma. MGG, obj. 100. fixação, porém, pode também ter utilidade quando se quer corar a lâmina por HE, no intuito de estabelecer uma correlação com as características tintoriais da neoplasia em questão com aquelas observadas na histopatologia de rotina e nos espécimes fixados por álcool hidratado $\left(96^{\circ} \mathrm{G}\right)$.

A secagem deficiente do material, antes de sua coloração pelo Wright ou pelo MGG dificultou a visualização do contraste núcleo/citoplasma.

No que diz respeito às observações comparativas sobre os diversos métodos tintoriais aplicados à citopatologia oncológica deste estudo (Quadro 1), considerou-se o Wright como corante do tipo Romanowsky de melhor resultado para exame de rotina. A familiaridade com a técnica permitiu maior praticidade, despendendo tempo máximo de 7 minutos. A coloração evidenciou o contraste núcleo-citoplasma, bem como a presença dos nucléolos (Fig. 4, 5, 6, 7, 8). Outra vantagem deste método é não haver necessidade de fixar o material. Acrescenta-se ainda como vantagem o fato de ser uma coloração permanente, possibilitando posterior análise da lâmina, após colocação de lamínula.

O May-Grünwald-Giemsa (MGG) proporcionou boa coloração (Fig. 1), sendo também permanente, sem necessitar de fixação da amostra. $O$ inconveniente residiu no fato de despender mais tempo (8-12 minutos). Observou-se também que o uso prolongado do corante alterou a tonalidade da coloração, que ficou mais clara, diminuindo o contraste celular.

O Novo Azul de Metileno (NAM) demonstrou boa praticidade, sem necessitar de fixação prévia. Os melhores resultados foram obtidos basicamente em lipomas e mastocitomas; em contrapartida, não corou os eosinófilos e os eritrócitos. Outros inconvenientes observados foram o fato de ser uma coloração provisória e de permitir boa avaliação apenas de núcleo e nucléolo. Utilizou-se esta técnica como coadjuvante do Wright no diagnóstico de mastocitomas pouco diferenciados.

O Papanicolau não se constituiu em um método prático, pois requereu maior tempo para preparação dos corantes e

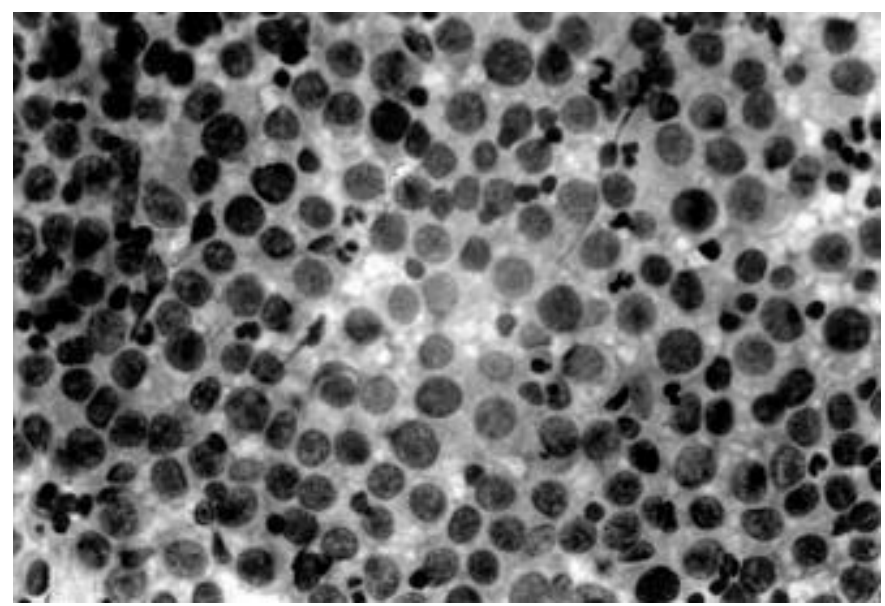

Fig. 2. "Imprint" de Tumor Venéreo Transmissível. Papanicolau, obj. 40. 

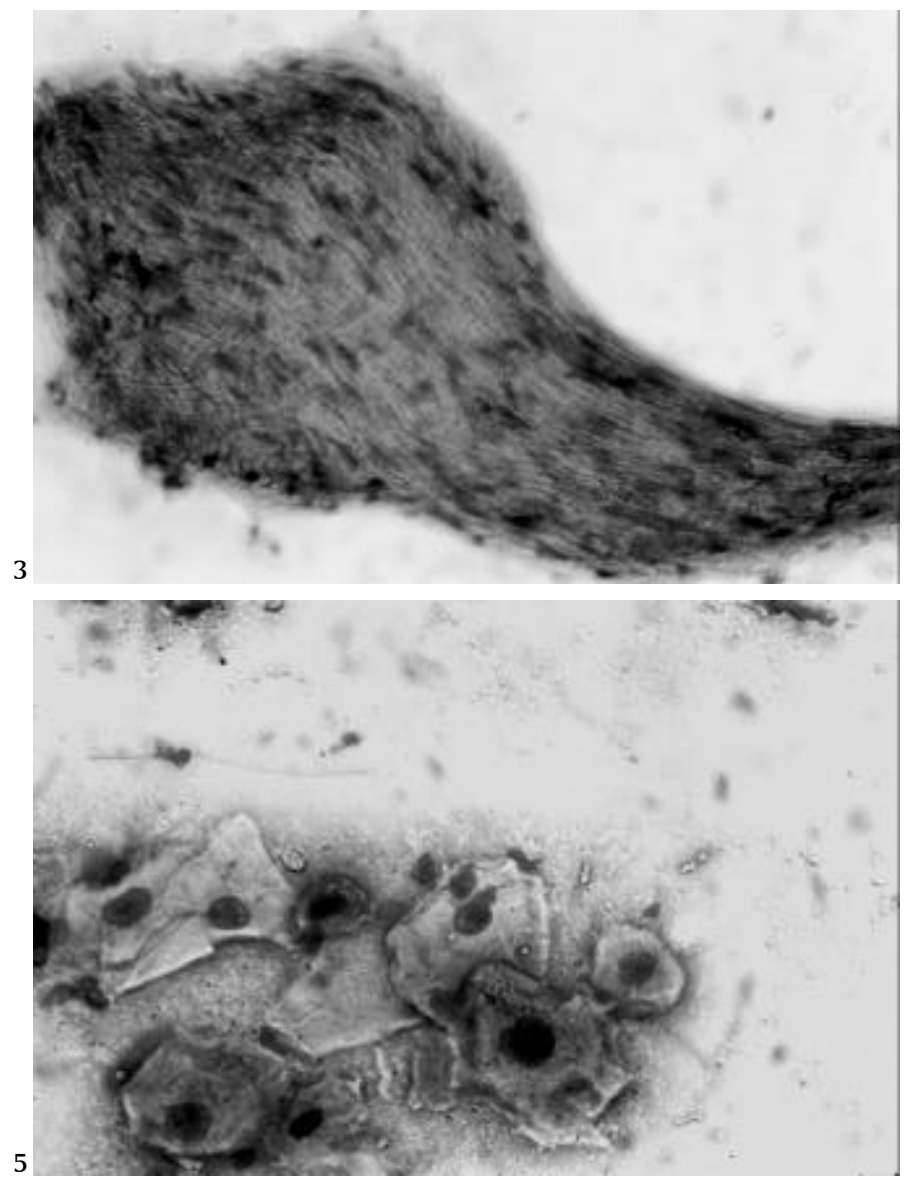

Fig. 3. Citologia esfoliativa de Leiomioma. Van Gieson, obj. 40.

Fig. 5. Citologia esfoliativa de Carcinoma de Células Escamosas. Wright, obj. 40

coloração das lâminas. Permite esta técnica uma nítida visualização do núcleo e do nucléolo, havendo, porém pouco contraste de cor com o citoplasma (Fig. 2). Adicionalmente, no caso de lâminas que não foram imediatamente fixadas em álcool hidratado, observou-se o inconveniente de encontrarem-se áreas com células já dessecadas.

A técnica de coloração $\mathrm{HE}$, a partir do emprego da Hematoxilina de Harris, mostrou-se eficiente e permitiu um exame citopatológico adequado, através do contraste estabelecido entre núcleo e citoplasma, com boa visualização do nucléolo e cromatina nuclear, principalmente em lipomas e tumor de células basais, quando comparada ao Wright.

A técnica de coloração com Azul de Toluidina foi eficaz para o diagnóstico de mastocitomas pouco diferenciados e indiferenciados, cujas granulações dos mastócitos foram pouco evidentes ou estavam ausentes nas colorações de Wright ou MGG. O inconveniente do corante é a sua vida útil de, no máximo, 15 dias após sua confecção.

Os achados citopatológicos encontrados no grupo das neoplasias de musculatura lisa, a partir do emprego do corante van Gieson, apresentaram características muito próximas às descritas pela histopatologia. A coloração foi considerada um
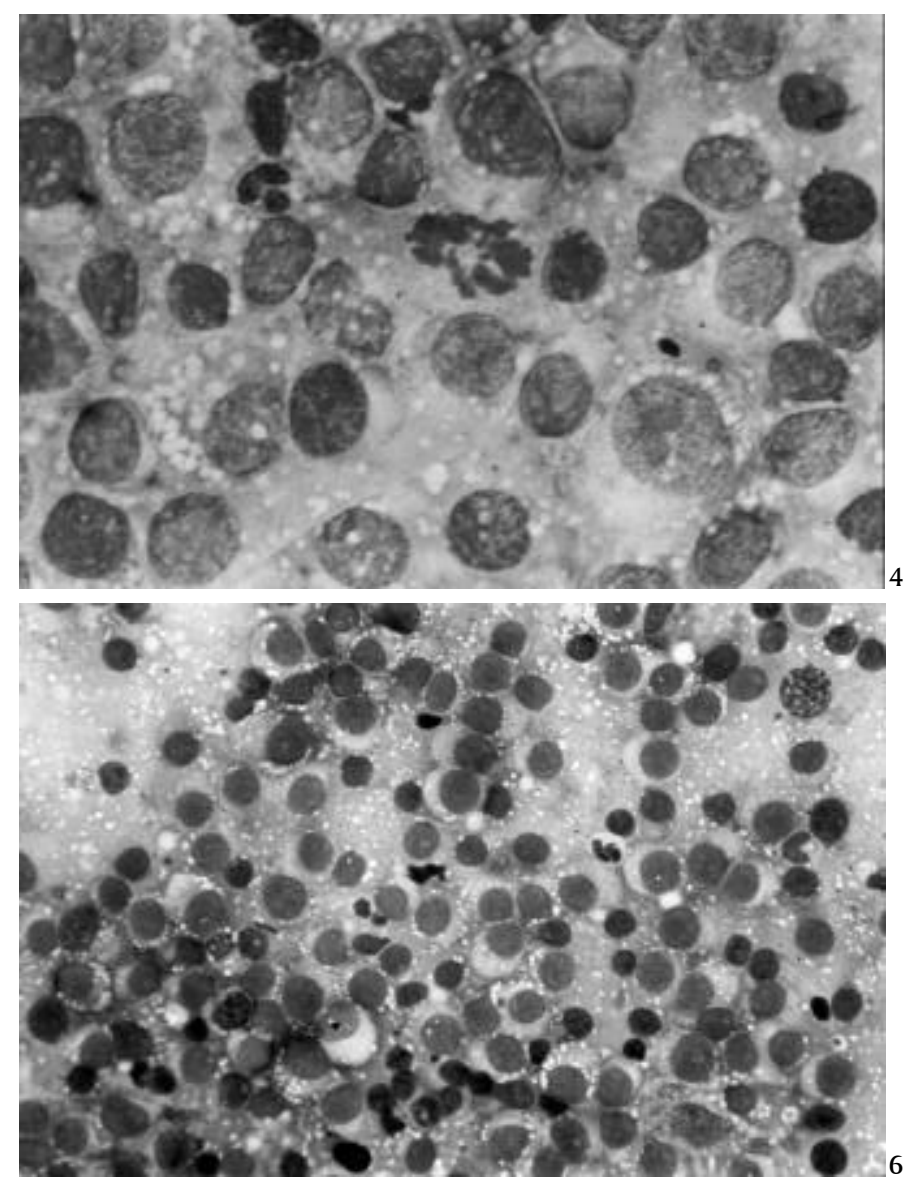

Fig. 4. Citologia esfoliativa de Tumor Venéreo Transmissível. Wright, obj. 1000.

Fig. 6. Citologia esfoliativa de Tumor Venéreo Transmissível. Wright, obj. 40.

método de apoio no diagnóstico citopatológico de leiomiomas e leiomiossarcomas (Fig 3).

As amostras de lipomas e lipossarcomas, submetidas à coloração de Sudan foram previamente fixadas em formol a $10 \%$. A técnica de coloração foi eficiente no sentido de fornecer dados mais concretos quanto à diferenciação das neoplasias. $\mathrm{O}$ único inconveniente foi relacionado à montagem. A glicerina não permitiu uma adequada impermeabilização, permanecendo úmida, o que tornou a coloração provisória. A coloração pelo $\mathrm{HE}$ mostrou-se bastante eficiente em ambos os tumores (Fig. 9).

O PAS foi igualmente testado em lâminas de tumor de células basais queratinizado, carcinoma epidermóide e mastocitoma pouco diferenciado. No primeiro e segundo casos, o estudo tornou-se inviável, pois a queratina impregnou-se de corante, assumindo uma tonalidade rósea forte, dificultando a observação das demais estruturas celulares e a definição da neoplasia. Em contrapartida, as poucas granulações presentes nos mastócitos foram nítidas ao exame citopatológico, confirmando as suspeitas clínicas e as características definidas pelos corantes do tipo Romanowsky. 

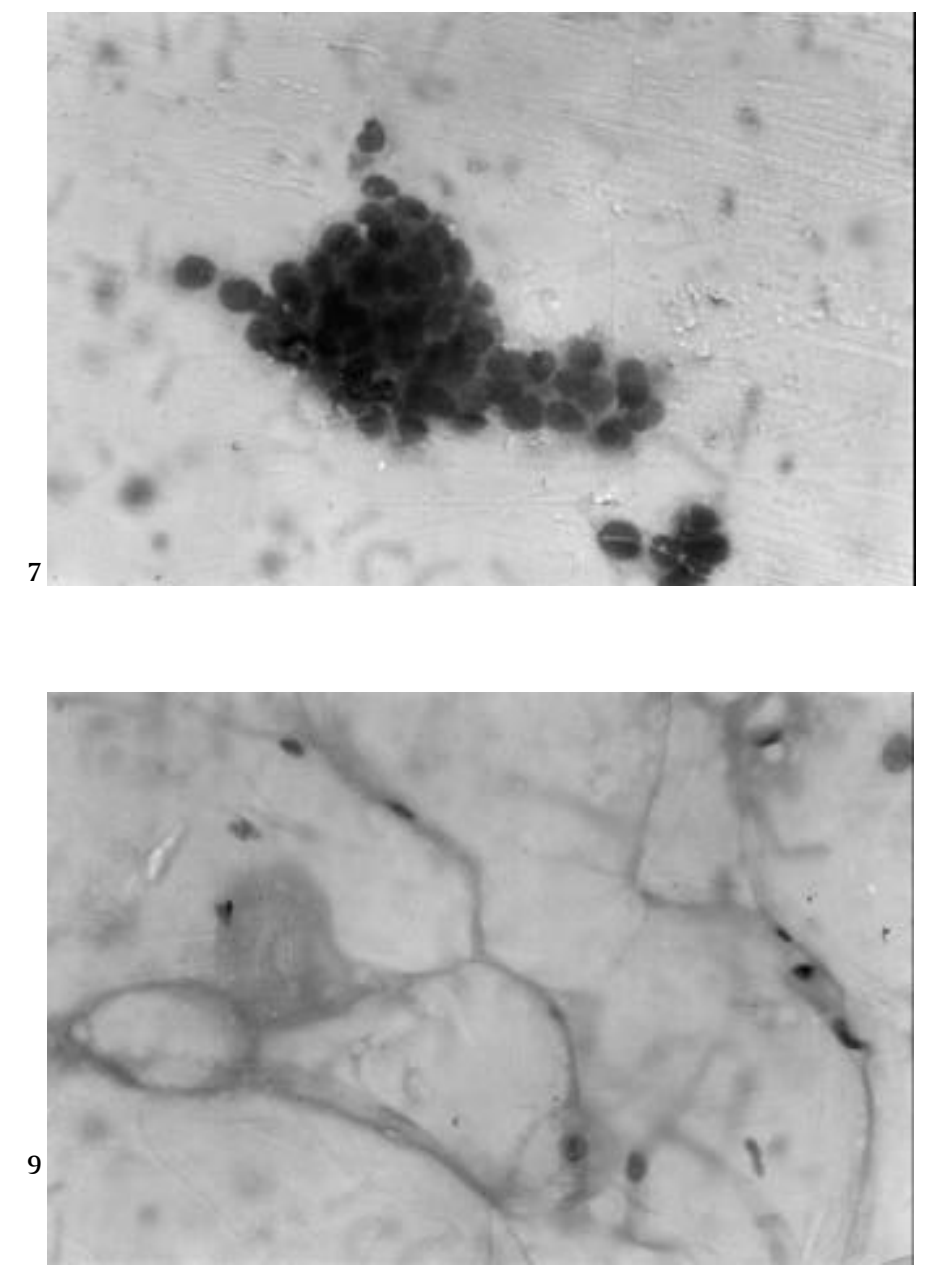

DISCUSSÃO E CONCLUSÕES

Concordando com a opinião registrada na literatura, a caracterização do tipo celular neoplásico pela citopatologia foi rápida, segura e eficaz (Wellman 1996, Guedes et al. 1997) possibilitando a identificação de diversos tipos de neoplasias em cães (Ogilvie \& Moore 1995, Montes O. 1997).

A margem de erro no diagnóstico citopatológico foi de $8,1 \%$, ressaltando a grande utilidade da citopatologia como meio diagnóstico para neoplasias em geral. Ainda em dois casos examinados, o diagnóstico definitivo foi estabelecido por esta técnica, em detrimento da histopatologia (Duncan $\&$ Prasse 1979). Reiterou-se a eficiência da histopatologia em detalhar a arquitetura do processo neoplásico e suas relações com tecidos circunjacentes, bem como em melhor caracterizar variações de diferenciação e tipos celulares, que não tenham sido bem definidos no exame citopatológico (Tvedten 1994, Lemarié et al. 1995).

Comprovadamente, as amostras colhidas através da PAAF apresentaram maior valor diagnóstico, quando comparadas à citopatologia esfoliativa ou impressão em lâminas (Tvedten 1994, Burkhard \& Meyer 1996).

Confirmou-se a eficiência da técnica desenvolvida por Ramadinha (1996), que empregou $2 \mathrm{ml}$ de ar na seringa, antes de introduzi-la na massa tumoral, obtendo-se por fim um gasto menor de tempo para a confecção da lâmina. Nos ca-

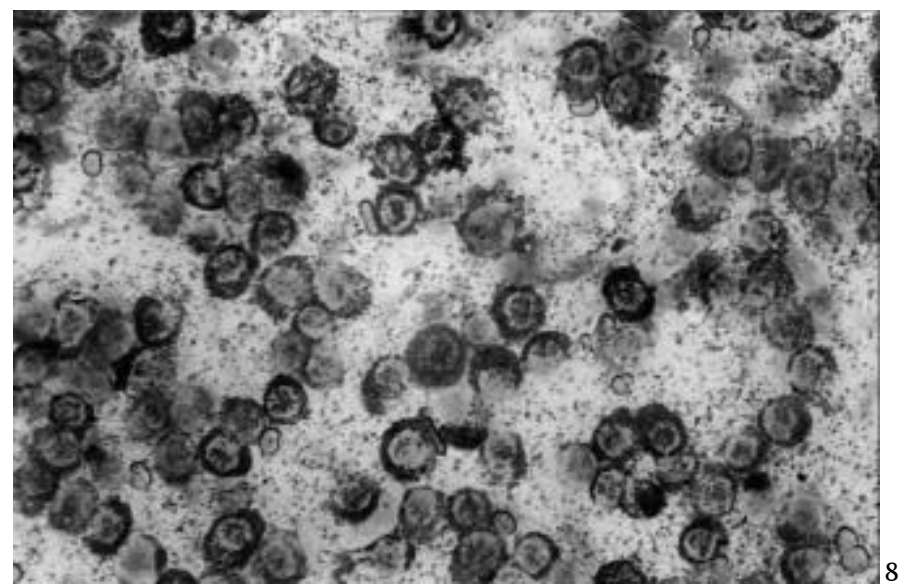

Fig. 7. Citologia aspirativa de Carcinoma Sólido. Wright, obj. 25.

Fig. 8. Citologia aspirativa de Mastocitoma. Wright, obj. 40.

Fig. 9. Citologia esfoliativa de Lipoma. HE, obj. 40.

sos de osteossarcoma, a agulha $40 \mathrm{X} 12$ foi mais eficaz para colheita (O’Rourke 1983, Ramadinha 1996).

A PAAF é, porém, de limitado valor em tumores mistos, esquirrosos ou naqueles com variável diferenciação celular. Nestes casos, verificou-se a necessidade de puncionar mais de um local, como já proposto por Tvedten (1994).

Deve ser destacada e confirmada a dificuldade de alguns autores em definir o tipo celular neoplásico nas áreas de inflamação, visto que fibroblastos reativos assemelhavam-se às células malignas (Cowell \& Tyler 1989b, Montes O. 1997).

De outro modo, a técnica de "imprint" foi eficiente para tumores bastante celulares, diminuindo a possibilidade de ruptura celular (O’Rourke 1983, Meyer \& Franks 1986a, Wellman 1990). Já em neoplasias pouco esfoliativas como sarcomas e alguns histiocitomas, foi de pouco valor diagnóstico, sendo substituída pela esfoliação através de lâmina de bisturi (Cowell \& Tyler 1989b).

Os melhores resultados tintoriais foram, por diversas vezes, obtidos com o corante Wright (Cowell \& Tyler 1989a,b, Wellman 1990). Como foi avaliado por alguns autores, o uso da coloração especial de Azul de Toluidina permitiu melhor visualização dos grânulos em mastocitomas indiferenciados (Susaneck 1983, Piza 1997). A definição citopatológica do padrão celular do lipossarcoma pelo Wright foi posteriormente confirmada pela coloração de Sudan (Meyer \& Franks 1986 b).

O diagnóstico citopatológico das linfoproliferações foi fácil, confirmando-se a precisão dessa técnica também para TVTs, mastocitomas e histiocitomas (Meyer \& Franks 1986b, Ogilvie \& Moore 1995). Em contrapartida, como foi observado por Mills (1989), houve limitações quanto à citopatologia aspirativa de linfonodo, quando da colheita de amostra de um único linfonodo ou de uma só área. O caso de micose fungóide, descrito neste estudo, teve diagnóstico citopa- 
tológico presuntivo, sendo bem definido através do exame histopatológico (DeBoer et al. 1990, Hewicker et al. 1990, Wellman 1990).

Discordamos das observações de Cowell \& Tyler (1989b) e Ogilvie \& Moore (1995), segundo as quais os tumores de células basais seriam passíveis de confusão com os histiocitomas. A experiência constatou que alguns carcinomas apresentaram certa semelhança citopatológica com tumores de células basais, ficando o diagnóstico definitivo na dependência da coloração de HE.

Com relação aos leiomiomas e leiomiossarcomas, a coloração de van Gieson definiu as características celulares típicas e estabeleceu fácil diferenciação com neoplasias originadas dos fibroblastos. Tais achados não foram anteriormente citados na literatura, referente à citopatologia.

Houve certa dificuldade no diagnóstico citopatológico das neoplasias melanocíticas, especialmente as classificadas como amelanóticas, como já observado por Meyer \& Franks (1986b), Chavez et al. (1997).

Ogilvie \& Moore (1995) afirmaram que os grânulos intracitoplasmáticos dos melanomas deveriam ser diferenciados dos tumores de mastócitos. Verificou-se, neste estudo, que o padrão celular difere entre os dois tumores e que as granulações dos melanomas têm coloração preta ou marrom, facilmente diferenciadas dos mastocitomas, principalmente em colorações especiais.

Houve dificuldade em determinar com precisão se a citopatologia aspirativa de tumor de mama correspondia a carcinoma ou adenocarcinoma. Isto foi constatado pela variação celular de área para área, dentro do mesmo tumor e nestes casos, a histopatologia estabeleceu o diagnóstico correto (Cowell \& Tyler 1989b, Withrow \& MacEwen 1996). De outro lado, os adenomas foram facilmente diferenciados dos carcinomas. Os tumores mistos muitas vezes não foram bem definidos, por dependerem da área que foi puncionada.

Levando-se em conta o acima exposto, fica claro que a citopatologia aplicada ao diagnóstico de neoplasias em Medicina Veterinária ainda encontra-se em estado incipiente. Há necessidade de avaliações comparativas dessa técnica com a histopatologia para uma gama maior de neoplasias nos animais domésticos. Além disso, percebe-se a necessidade de introdução de novas técnicas de colorações específicas mais conclusivas para as neoplasias, a partir das técnicas histológicas de coloração.

\section{REFERÊNCIAS}

Allen S.W. \& Prasse K.W. 1986. Cytologic diagnosis of neoplasia and perioperative implementation. Comp.Cont.Educ. 8(2):72-80.

Barton C.L. 1983. Cytologic diagnosis of neoplastic disease: an Algorithm. Texas Vet. Med. J., Small Animal Medicine :11- 13.

Boon G.D., Rebar A.H. \& DeNicola, D.B. 1982. A cytologic comparison of Romanowsky stains and Papanicolau-type stains. I. Introduction, methodology and cytology of normal tissues. Vet. Clin. Pathol. 11(1):2230 .

Bracarense A.P.F.R.L., Reis A.C.F. \& Viotti N.M.A. 1993. Estudo comparativo entre o exame citológico e histopatológico nas neoplasias dos animais domésticos. Anais XV Congr. Bras. da Anclivepa, Rio de Janeiro, p.139. (Resumo)
Burkhard M.J. \& Meyer D.J. 1996. Invasive cytology of internal organs - cytology of the thorax and abdomen. Vet. Clin. North America, Small Animal Practice 26(5):1203-1222.

Carvalho G. 1993. Citologia Oncológica. Atheneu Editora, São Paulo. 290p.

Castillo C.A., Candanosa E.A. \& Buen N.A. 1988. Diagnóstico citológico en veterinaria, análisis de 3563 casos. Vet. Méx. 19:211-215.

Castro M.B., Moreira M.M., Casagrande A.M., Franco S.R.V.S. \& Fabris V.E. 1993. Manifestação cutânea do tumor venéreo transmissível (TVT) em cães - relato de 2 casos. Anais XV Congr. Bras. Anclivepa, Rio de Janeiro, p.145. (Resumo)

Chavez M.A., Pessatti L.E., Carfagnini J.C. \& Blanco D.F. 1997. Uso de marcadores específicos para el estudio diagnóstico del melanoma canino. In: $2^{\text {as }}$ Jornadas Hospitalarias de Medicina Veterinaria, Buenos Aires, p.174175.

Clinkenbeard K.D. 1992. Diagnostic cytology: carcinomas in pleural effusions. Comp. Cont. Education 14(2):187-194.

Coelho S.O. 1996. Sulfato de vinblastina na quimioterapia do tumor venéreo transmissível em cães (Canis familiaris): perfil clínico e laboratorial. Tese de Mestrado, Univ. Fed. Rural do Rio de Janeiro. 37p.

Couto C.G. 1994. Cytology in the diagnosis of cancer. TNAVC - Proceedings in Small Animal Clin. Pathol., p.91-93.

Cowell R.L. \& Tyler R.D. 1989a. Diagnostic Cytology of the Dog and Cat. Am. Vet. Publ., USA. 259p.

Cowell R.L. \& Tyler R.D. 1989b. Cytology of cutaneous lesions. Vet. Clin. North America, Small Animal Practice 19(4):769-794.

Cunha M.M.P.L. 1987. Manual de Laboratório Cito-histopatológico. Ministério da Saúde, Secretaria Nacional de Programas Especiais de Saúde, Divisão Nacional de Saúde Materno-Infantil, Divisão Nacional de Laboratórios de Saúde Pública, Centro de Documentação do Ministério da Saúde, Série A: Normas e Manuais Técnicos, Brasília. 43p.

DeBoer D.J., Turrel J.M. \& Moore P.F. 1990. Mycosis fungoides in a dog: demonstration of T-cell specificity and response to radiotherapy. JAAHA 26: 566-572.

De Paula L.F., Ferreira H., Peres J.A., Teixeira R.B. \& Franco A.P.R. 1997. Metástase de tumor venéreo transmissível em figado e baço - relato de um caso. Anais XIX Congr. Bras. Anclivepa, Curitiba, p. 9. (Resumo)

Duncan J.R. \& Prasse K.W. 1979. Cytology of canine cell tumors (mast cell tumor, histiocytoma, lymphosarcoma and transmissible veneral tumor). Vet. Path. 16(4):673-679.

Edwards D.F. 1994a. Cytology: Beginner's guide. TNAVC - Proceedings in Small Animal Clinical Pathol. :95-96.

Felizzola C.R. 1995. Estudo comparativo de neoplasias bucais em cães - avaliação dos aspectos clínicos, da histopatologia e citologia esfoliativa. Tese de Mestrado, Fac. Med. Vet. e Zoot. Universidade de São Paulo, SP. 80p.

French T.W. 1987. The use of cytology in the diagnosis of chronic nasal disorders. Comp. Cont. Education. - Small Animal 9(2):115-120.

Guedes R.M.C., Nogueira R.H.G. \& Tudury E.A. 1997. Diagnóstico citológico de lesões proliferativas e inflamatórias através da técnica de punção de tecidos com agulha fina. Hora Veterinária, Porto Alegre, 16(96):15-21.

Hewicker M., Beardi B., Zipfel W., Opitz M. \& Trautwein G. 1990. Epidermotropes Lymphosarkom (Mycosis fungoides) bei einem Hund. Tierärztl. Prax. 18:633-639.

Humason G.L. 1962. Animal Tissue Techniques. $1^{\text {st }}$ ed. W.H. Freeman and Company, USA. 468p.

Lemarié R.J., Lemarié S.L. \& Hedlund C.S. 1995. Mast cell tumors: clinical management. Comp. Cont. Education, Small Animal Oncology 17(9):10851101.

Machado L.H.A., Moutinho F.Q., Barbosa M.V.F., Biasi F., Lourenço M.L.G., Mamprim M.J., Monteiro J.R. \& Bandarra, E.P. 1997a. Linfoma esplênico em cão jovem - relato de caso. Anais XIX Congr. Bras. Anclivepa, Curitiba, p.10. (Resumo)

Machado L.H.A., Moutinho F.Q., Barbosa M.V.F, Peres J.A., Rocha A.A.F., 
Mamprim M.J. \& Rocha N.S. 1997b. Mieloma múltiplo em canino - relato de caso. Anais XIX Congr. Bras. Anclivepa, Curitiba, p.11. (Resumo)

Melchert A., Peres J.A., Moutinho F.Q. \& Rocha N.S. 1997. Tumor venéreo transmissível com acometimento cutâneo e de linfonodos - relato de um caso. Anais XIX Congr. Bras. Anclivepa, Curitiba, p.10. (Resumo)

Mello M.L.V. \& Santos M.R.C. 1996. Avaliação clínica e citológica de TVT canino. XV Congr. Panamericano de Ciências Veterinárias, Campo Grande, p.135. (Resumo)

Mello M.L.V., Santos M.R.C. \& Almeida L.E. 1996. Citologia vaginal e tratamento de cadelas com TVT. XV Congr. Panamericano de Ciências Veterinárias, Campo Grande, p.137. (Resumo)

Meyer D.J. 1987. The management of cytology specimens. Comp. Cont. Education - Small Animal 9(1):10-17.

Meyer D.J. \& Franks P. 1986a. Clinical cytology - management of tissue specimens. Modern Veterinary Practice :255-259.

Meyer D.J. \& Franks P. 1986b. Clinical cytology - cytologic characteristics of tumors. Modern Veterinary Practice :440-445.

Mills J.N. 1989. Lymph node cytology. Veterinary Clinics of North America, Small Animal Practice, Clinical Pathology 19(4):697-717.

Mills J.N. \& Griffiths G.L. 1984. The accuracy of clinical diagnoses by fineneedle aspiration cytology. Aust. Vet. J. 61(8):269-271.

Montes O.G.A. 1997. Citologia en la clinica medica de pequeños animales. In: $2^{\mathrm{a}}$ Jornadas Hospitalarias de Medicina Veterinaria, Buenos Aires, p.111-117.

Moriello K.A. \& Rosenthal R.C. 1990. Clinical approach to tumors of the skin and subcutaneous tissues. Vet. Clin. North America - Small Animal Practice 20(4):1163-1190.

Morrison W.B. \& DeNicola D.B. 1993. Advantages and disadvantages of cytology and histopathology for the diagnosis of cancer. Seminars in Veterinary Medicine and Surgery (Small Animal) 8(4):222-227.

Ogilvie G.K. \& Moore A.S. 1995. Managing the veterinary cancer patient - a practice manual. $1^{\text {st }}$ ed. Veterinary Learning Systems, USA, p.37-51.

Olson P.N., Thrall M.A., Wykes P.M. \& Nett T.M. 1984a. Vaginal cytology. Part I. A useful tool for staging the canine estrous cycle. Comp. Cont. Education 6(4):288-297.

O’Rourke L.G. 1983. Cytologic technics: sampling, slide preparation, staining. Modern Veterinary Practice :185-189.

Peterson J.L. \& Couto C.G. 1994. Tumors of the skin and subcutaneous tissues, p.211-217. In: Birchard S.J., Sherding R.G. (ed.) Saunders Manual of Small Animal Practice. $1^{\text {st }}$ ed. W.B. Saunders Company, Philadelphia.

Piza E.T. 1997. Comunicação pessoal (Faculdade de Medicina Veterinária Plínio Leite, Itaboraí, RJ).

Ramadinha R.R., 1996. Comunicação pessoal (Universidade Federal Rural do Rio de Janeiro, Seropédica, RJ).

Ramadinha R.R., Santiago C.A.D. \& Magalhães A.M. 1995. Ocorrência de tumores cutâneos em cães e gatos no Rio de Janeiro. Anais XVII Congr. Bras. Anclivepa, Vitória, p. 58. (Resumo)

Rebar A.H., Boon G.D. \& DeNicola D.B. 1989. A cytologic comparison of Romanowsky stains and Papanicolau-type stains. II. Cytology of inflammatory and neoplastic lesions. Vet. Clin. Path. 11(2):16-25.

Rocha A.A.F., Sakate M., Franco S.R.V.S., Moura V.M.B.D., Rocha N.S., Fabretti J.T. \& Fabris V.E. 1997. Tumor venéreo transmissível cutâneo - relato de um caso. Anais Congr. Bras. Anclivepa, Curitiba, p.11.

SBHH - Sociedade Brasileira de Hematologia e Hemoterapia - Comitê de padronização em hematologia 1975. XII Congr. Bras. SBHH, São Paulo.

Schmitt F.C. 1995. Autópsias, biópsias e citopatologia: o que são e como são utilizados. In: Andrade Z., Netto M.B., Brito T. \& Montenegro M.R. Patologia - processos gerais. $3^{\mathrm{a}}$ ed. Atheneu, Rio de Janeiro, p. 255263.

Schwartz D.S., Melo F., Biondo A.W., Kohayagawa A. \& Sequeira J.L. 1994. Aspectos clínico-laboratoriais de linfoma em cães: descrição de 17 casos. Anais XVI Congr. Bras. Anclivepa, Goiânia, p.16. (Resumo)

Seybold I., Goldston R.T. \& Wikes R.D. 1982. Exfoliative cytology. Vet. Med. Small Animal Clinician 77(7):1029-1033.

Silveira J.M. 1988. Patologia Clínica Veterinária - teoria e interpretação. $1^{\mathrm{a}}$ ed. Editora Guanabara-Koogan, Rio de Janeiro, p. 98-111.

Susaneck S.J. 1983. Feline skin tumors. Comp. Cont. Education 5(4):251-259.

Tvedten H. 1981. Cytology of neoplastic and inflammatory masses, p.327348. In: Willard M.D., Tvedten H. \& Turnwald G. (ed.) Small Animal - Clinical diagnosis by laboratory methods. $2^{\text {nd }}$ ed. W.B.Saunders Company, Philadelphia.

Tvedten H. 1994. Cytology of neoplastic and inflammatory masses, p.321341. In: Willard M.D.; Tvedten H. \& Turnwald G. (ed.) Small Animal - Clinical Diagnosis by Laboratory Methods. $2^{\text {nd }}$ ed. W.B. Saunders Company, Philadelphia.

Vannucchi C.I., Satzinger S., Santos S.E.C. 1997. Técnica de citologia vaginal como método de diagnóstico da fase do ciclo estral em cadelas. Clínica Veterinária 2(9):14-19.

Xavier S.P., Latorre J.O.M., Dutra T.R., Magalhães A.M. \& Ramadinha R.R. 1997. Eficácia da vinblastina no tratamento do tumor venéreo transmissível canino. Anais XIX Congr. Bras. Anclivepa, Curitiba, p. 8. (Resumo)

Wellman M.L. 1990. The cytologic diagnosis of neoplasia. Vet. Clin. North America - Small Animal Practice 20(4):919-938.

Wellman M.L. 1996. Cytology and the diagnosis of neoplasia. 20th Annual Waltham Symposium for the Treatment of Small Animal Diseases (Oncology and Hematology), p.11-20.

Withrow S.J. \& MacEwen E.G. 1996. Small Animal Clinical Oncology. $2^{\text {nd }}$ ed. W.B. Saunders Company, Philadelphia, p. 589. 